\title{
Nursing and midwifery students' perceptions of educational environment and grade point average: a comparison between nursing and midwifery students
}

\author{
Zahra Marzieh Hassanian ${ }^{1}$, Khodayar Oshvandi ${ }^{2}$
}

${ }^{1} \mathrm{PhD}$ of Nursing, Assistant Professor, Department of Nursing, Chronic Disease Home Care Research Center, Hamadan University of Medical Sciences, Hamadan, Iran

${ }^{2} \mathrm{PhD}$ of Nursing, Associate Professor, Department of Medical and Surgical Nursing, Mother and Child Care Research Center, Hamadan University of Medical Sciences, Hamadan, Iran

\section{Type of article: Original}

\begin{abstract}
Background: The educational environment is an essential component of student learning. Study of the educational environment is crucial to provision of a learning quality, student-centered program for nursing and midwifery fields.

Objective: The aim of this study was to determine the associations between baccalaureate nursing and midwifery students' perceptions of educational environment (SPEE) and grade point average (GPA), and comparison between students of nursing and midwifery field.

Methods: A cross-sectional study was conducted in Hamadan Nursing and Midwifery Faculty. In this study, 249 nursing and 59 midwifery students participated. The study period lasted 12 months. We used an Iranian -language version of the Dundee Ready Education Environment Measure (DREEM) questionnaire to measure nursing and midwifery students' perceptions of the educational environment. The data analysis was performed using descriptive statistic, Pearson's coefficient, Spearman's coefficient, and independent t-test through the SPSS version 16 . P-value less than 0.05 were considered statistically significant.

Results: There was significant difference in nursing and midwifery students in perceptions of learning (SPL) $(\mathrm{p}=0.0001)$, perceptions of Teaching (SPT) $(\mathrm{p}=0.009)$, Academic self-perceptions (SASP) $(\mathrm{p}=0.005)$ and perceptions of educational environment. There was correlation between categories' perceptions of teaching and GPA $(p=0.016)$, academic self-perceptions and GPA $(p=0.001)$. Moreover, there was correlation between perceptions of educational environment and GPA $(\mathrm{p}=0.028)$.

Conclusion: Although there was significant difference in nursing and midwifery students in perceptions of the educational environment, there was straight correlation between the educational environment and GPA, and there is opportunity for development of the educational environment. As the discipline of nursing education advances, there is need to develop the learning environment in areas of perceptions of teaching and academic selfperceptions, to build an effective learning environment for attaining better GPA, which addresses nursing educational managers and considers items beyond college, like social topics. Furthermore, it requires studying the effect of the learning environment on educational outcome in Iranian nursing and midwifery faculties.
\end{abstract}

Keywords: Educational environment; Grade point average; Midwifery; Nursing

\section{Introduction}

The educational environment is one of the most important determining issues of an effective curriculum (1). Perception of the educational environment may be categorized as the educational climate and the EC is revealed to mean everything that occurs in the educational area, such as in a schoolroom, the nursing faculty, or in the university

\section{Corresponding author:}

Associate Professor Dr. Khodayar Oshvandi.

Tel: +98.8138380150, Fax:+98.8138380447, Email: oshvandi@umsha.ac.ir

Received: June 29, 2017, Accepted: November 23, 2017, Published: July 2018

iThenticate screening: November 03, 2017, English editing: April 05, 2018, Quality control: April 15, 2018

This article has been reviewed / commented by four experts

Ethics approval: 88061788283, Hamadan University of Medical Sciences

(C) 2018 The Authors. This is an open access article under the terms of the Creative Commons Attribution-NonCommercialNoDerivs License, which permits use and distribution in any medium, provided the original work is properly cited, the use is non-commercial and no modifications or adaptations are made. 
(2). The World Federation for Medical Education in 1998 stressed the learning environment as one of the goals for the evaluation of the medical education program (3). The school climate is established on the public's experiences of faculty life, and discloses norms, goals, values, interpersonal relationships, instruction and learning, and organizational structures (4). Climate concepts debate the total environmental quality in an organization (5). It is widely agreed between medical instructors that the academic environment has significant impact on the attitudes, knowledge, skills and progression of students (6). Students' perception of the educational environment (SPEE) has been revealed to impact students carrying out a particular learning style and impacts educational outcomes like grade point average (GPA) (7). It is suggested, faculties create an educational state to transfer and implement knowledge as well as to provide grounds for applying knowledge by displaying objects (8). A student-focused learning environment is associated with autonomy in learning, innovative problem-solving skills, an obligation to life-long education and critical thinking (9). Students' perception of the EC has been revealed to have an important influence on their performance, academic development and sense of well-being (10). Other researchers such as Payne (2014) declared that students' performance was not affected by SPEE (11). Student satisfaction is an essential sign of the quality of learning experiences and is associated to some consequence variables such as GPA. The evaluation of the educational environment is important to the provision of a high-quality, student-centered program (12). The best broadly used contemporary advance is the Dundee Ready Education Environment Measure (DREEM) (13). The DREEM is a tool intended for measurement of EC precisely for undergraduate medical education (14). The debate regarding school climate and its influence on students' achievement are between researchers. Furthermore, universities and nursing and midwifery faculties' managers provide facilities for nursing and midwifery's students, but it appears that nursing students' perceptions are not the same as midwifery students' perceptions in a number of dimensions in faculties. In the community, many people believe in focusing on the nursing shortage and the ability, on the other hand, nurse educators attempt to offer a workforce that meets the increasing demand and the progressive needs of public. Nursing teachers try to build a student-focused environment encouraging learning, increasing student knowledge and GPA similar to midwifery students. It seems that perceptions of nursing and midwifery in faculty differ from one another, so researchers decided to study about perceptions of the educational environment and grade points, and compare the differences between nursing and midwifery students. Researchers did not find any article about comparing the perception of nursing and midwifery students separately regarding the learning environment and the relationship with the GPA. The purpose of this study was to determine the relationship between BSN nursing and midwifery SPEE and GPA and differences between students of nursing and midwifery field.

\section{Material and Methods \\ 2.1. Design and setting}

A cross-sectional study was done in Hamadan Nursing and Midwifery Faculty. A structured questionnaire comprising contextual characteristics and DREEM questionnaire was applied and the data was gathered. Participants were selected by census sampling.

\subsection{Sample size and data collection}

In this study, 245 nursing and 63 midwifery baccalaureate students were chosen from 2nd semester to 4th year. Students of the first semester were omitted due to deficiency of knowledge on various parts of faculty and to decrease bias in the study. This study was carried out in a nursing and midwifery school that admitted nursing students (two courses in both semesters) in each year, while midwifery students were admitted in limited number only in one semester in each year.

\subsection{Instrument}

DREEM has been widely used as an instrument to gathered information about the educational environment in many institutions (15). The five subscales of the learning environment are recognized as students' perception of learning, students' perception of teachers, students' academic self-perceptions, students' perception of atmosphere and students' social self-perceptions. The DREEM instrument is constructed to assess students' perception of the education climate (15). The DREEM instrument is a 50 -item, self-administered, Likert-style questionnaire extending from 0 (strongly disagree) to 4 (strongly agree). Of the 50 items, 9 are conversely scored; so a lesser score is desired. There are 5 separate components of the DREEM questionnaire and their maximum scores are: Students' (SPL): 12 items (items 1, 7, 13, 16, 20, 22, 24, 25, 38, 44, 47 and 48) (extreme score 48), (SPT): 11 items (items 2, 6, 8, 9, 18, 29, 32, 37, 39, 40 and 50) (extreme score 44), Students' (SASP): 8 items (items 5, 10, 21, 26, 27, 31, 41 and 45) (extreme score 32), Students' (SPA): 12 items (items 11, 12, 17, 23, 30, 33, 34, 35, 36, 42, 43 and 49) (extreme score 48), and (SSSP): 7 items (items 3, 4, 14, 15, 19, 28 and 46) (extreme score 28) (7). The DREEM instrument 
has also been used to assess (1) in nursing faculties (16), (17). Roff (2005) indicated the internal consistency reliability of the DREEM instrument to be 0.91 (15). We used an Iranian language form of the DREEM questionnaire that had been validated and used earlier (18). Prior to applying, a pilot study was done to ensure that the different objects were well understood by nursing and midwifery students, and then finally, the questionnaire was put into this study. The internal reliability in this study was 0.86 (Cornbrash's alpha). The students were requested to give response the questionnaires in a noiseless setting and the researcher gathered the questionnaires after the completion, the next day.

\subsection{Data Analysis}

The SPSS 16 program was used to describe the study population through descriptive statistic, Pearson's coefficient, Spearman's coefficient, independent t-test was used to analyze the study data with a p-value of 0.05 considered statistically significant.

\subsection{Ethical Consideration}

The study was approved by the Medical Research Committee of the Hamadan University of Medical Sciences (Ref. no.: 88061788283). The participants took part in this study through informed consensus voluntarily, also their characteristics were not revealed and the results were published collectively. The Researcher delineated the objectives of the study to the students and how the data would be preserved, before collecting data. This paper is the result of an approved research plan funded by UMSHA vice president, for research purposes. The authors wish to thank the vice-chancellor on research in Hamadan University of Medical Sciences who supported this study, and thank all nursing and midwifery students for their great help in conducting this research.

\section{Results}

In this study, generally, $84.15 \%$ of the questionnaires were completed and returned by students. According to the results of the study, the age range of the nurses was 19-25 years. Furthermore, $202(65.6 \%)$ of the participants were within the age ranges of 19-22 and $86(27.9 \%)$ of the participants were within the age ranges of 23-25 years, and 20 $(6.5 \%)$ of the participants were within the age ranges of $>25$, respectively. As the results demonstrated, $26(8.4 \%)$ of students were second semester students, $88(28.5 \%)$ were second year students, $83(27 \%)$ third year students and $111(36.1 \%)$ fourth year students. Furthermore, $26(8.4 \%)$ of students were in part time work. In this study, 245 (79.6\%) of the students were in the nursing field and $63(20.4 \%)$ were in midwifery, $245(79.6 \%)$ were female and $84(27.3 \%)$ were male. The age range of $202(65.6 \%)$ students was between 19 and 22, $86(27.9 \%)$ students were between 22 and 25 , and $20(6.5 \%)$ students were $>25$ years. The majority of participants were nursing students due to be admitted for two-semesters in each year, and midwifery students were admitted for one semester in each year. Mean scores and STD of students' perception of educational environment by nursing and midwifery students is calculated, based on findings, the total result of the DREEM study in nursing students was 146.00 (22.47) and in midwifery students 157.86 (25.63) of a total of 200 points. Mean scores and STD on areas by nursing and midwifery students and difference of means in nursing and midwifery students are shown in Table 1 . In the analysis of the total DREEM study, results of Mean and STD scores in nursing students was 146.00 (22.47) and in midwifery students 157.86 (25.63) of a total of 200 points, which displayed that the average score acquired by midwifery students was higher than that of the nursing students. However, (SPL) in the nursing field was 31.77 (7.145) and in the midwifery field was 36.88 (7.64), perception of midwifery students was more than that of the nursing students, difference of means was a significant $(\mathrm{t}=4.87, \mathrm{p}=0.0001)$ and both nursing and midwifery fields interpreted A more positive perception. In nursing, (SPT) was 32.76 (5.611) and in midwifery was 34.95 (6.132), perception of midwifery students was more than that of the nursing students, difference of means was significant $(t=2.647, p=0.009)$ and the nursing field interpreted Moving in the right direction and the midwifery field, Model Instructors. (SASP) in the nursing field was 23.12 (5.115), interpreted Feeling more on the positive side, in midwifery was 25.29 (5.907), interpreted Confident, perception of midwifery students was more than nursing students and difference of means was significant $(\mathrm{t}=2.833, \mathrm{p}=0.005)$. (SPA) in nursing was 37.88 (7.370) and in midwifery was 39.75 (7.510), perception of midwifery students was more than in nursing students and difference of means was $(\mathrm{t}=1.739$, $\mathrm{p}=0.083$ ), both fields interpreted A good feeling overall. (SSSP) in nursing was 20.47 (4.470), in midwifery was 21.00 (4.461), perception of midwifery students was more than in nursing students, difference of means was $(\mathrm{t}=0.826, \mathrm{p}=0.410)$ and both fields interpreted Not too bad. Perceptions of educational environment (SPEE) in nursing was 146.00 (22.478) and interpreted More positive than negative, in midwifery was 157.86 (25.632) and interpreted Excellent, difference of means was a significant difference $(\mathrm{t}=3.545, \mathrm{p}=0.0001)$ and perception of midwifery students was more than in nursing students. Table 2 shows the correlations between areas of nursing and midwifery students' perception and total students GPA. In this study, there was correlation, significant between 
areas (SPT) and GPA $(\mathrm{t}=0.150, \mathrm{p}=0.016),(\mathrm{SASP})$ and GPA $(\mathrm{t}=0.275, \mathrm{p}=0.001)$. There was also correlation between (SPEE) and GPA $(\mathrm{t}=0.137 \mathrm{p}=0.028)$. The score for nursing students was low and the score for midwifery students was low, but the score for nursing students was less than that of midwifery students. The correlation coefficient in (SASP) and (SPEE) between the two variables was weak, due to the low number admission of midwifery students than nursing students, and if the number of midwifery students had been increased, the result would be meaningful.

Table 1. Mean scores and STD. on categories and Difference of means in nursing and midwifery students

\begin{tabular}{|l|l|l|l|}
\hline Area score* & \multicolumn{2}{|l|}{ Field of study } & p-value \\
\cline { 2 - 4 } & Nursing $(\mathrm{n}=249)$ & Midwifery $(\mathrm{n}=59)$ & \\
\hline Perceptions of learning (SPL) & $31.77 \pm 7.14$ & $36.88 \pm 7.64$ & 0.0001 \\
\hline Perceptions of Teaching/Instructors (SPT) & $32.76 \pm 5.611$ & $34.95 \pm 6.132$ & 0.009 \\
\hline Academic self-perceptions (SASP) & $23.12 \pm 5.115$ & $25.29 \pm 5.907$ & 0.005 \\
\hline Perception of Atmosphere (SPA) & $37.88 \pm 7.370$ & $39.75 \pm 7.510$ & 0.083 \\
\hline Social Self Perceptions (SSSP) & $20.47 \pm 4.470$ & $21.00 \pm 4.461$ & 0.410 \\
\hline perceptions of educational environment (SPEE) & $146.00 \pm 22.478$ & $157.86 \pm 25.632$ & 0.0001 \\
\hline
\end{tabular}

* Data are presented as mean \pm standard deviation

Table 2. Correlations between categories and nursing and midwifery students GPA

\begin{tabular}{|l|l|l|l|}
\hline Area score & Field GPA & Correlation Coefficient & $\mathrm{p}$-value \\
\hline Perceptions of learning (SPL) & Nursing & -0.003 & 0.971 \\
\cline { 2 - 4 } & Midwifery & 0.130 & 0.401 \\
\cline { 2 - 4 } & Total students & 0.099 & 0.116 \\
\hline \multirow{3}{*}{ Perceptions of Teaching/Instructors (SPT) } & Nursing & 0.097 & 0.161 \\
\cline { 2 - 4 } & Midwifery & 0.134 & 0.386 \\
\cline { 2 - 4 } & Total students & 0.150 & 0.016 \\
\hline \multirow{3}{*}{ Academic self-perceptions (SASP) } & Nursing & 0.163 & 0.018 \\
\cline { 2 - 4 } & Midwifery & 0.275 & 0.070 \\
\cline { 2 - 4 } & Total students & 0.213 & 0.001 \\
\hline \multirow{3}{*}{ Perception of Atmosphere (SPA) } & Nursing & 0.015 & 0.831 \\
\cline { 2 - 4 } & Midwifery & 0.104 & 0.500 \\
\cline { 2 - 4 } & Total students & 0.045 & 0.470 \\
\hline Social Self Perceptions (SSSP) & Nursing & 0.024 & 0.731 \\
\cline { 2 - 4 } & Midwifery & 0.102 & 0.508 \\
\cline { 2 - 3 } & Total students & 0.035 & 0.573 \\
\hline Perceptions of educational environment (SPEE) & Nursing & 0.069 & 0.316 \\
\cline { 2 - 3 } & Midwifery & 0.253 & 0.097 \\
\cline { 2 - 3 } & Total students & 0.137 & 0.028 \\
\hline
\end{tabular}

\section{Discussion}

In the analysis of the total DREEM study, results of Mean scores and STD deviation in nursing students was 146.00 (22.47) and in midwifery students 157.86 (25.63) of a total of 200 points, which shows that the average score obtained by midwifery students was higher than that of nursing students. Total results revealed students perception of two field students were higher than previous studies, the overall DREEM maximum score for MEDRADSC in the study of Lumsden et al. was 138.8 (19) and in the Cerón et al.'s study, was 133 (20); however, there is still opportunity for upgrading of the EC from the viewpoint of the students. This is crucial to managers' developing strategies to enhance educational environment perception. Lizzio found that students' perceptions of their learning environment was a stronger predictor of learning consequences at academies (7). Similarly, in an educational environment such as nursing and midwifery faculties, knowledge must be created, acquired, shared and used to enhance learning and create practical knowledge (21). As Pimparyon's study revealed, students with a positive learning environment were more educationally prosperous (2). In this study, there was significant difference in nursing and midwifery students in (SPL), (SPT), (SASP) area and (SPEE). There was no significant difference in nursing and midwifery students in (SSSP) and (SPA) areas. In a study by Tontus, there were significant differences between two research groups of students regarding EC (14). Payne showed that there was no significant difference in student perceptions of EC between the traditional and accelerated cohorts at this organization as assessed by the DREEM instrument except the sub-domain, Perceptions of Atmosphere (SPA) (22). Findings of this study were the 
same as those of the Tontus study but differed to the study by Payne. The difference is probably due to differences in study population. Taheri found that both groups of students perceived the learning environment relatively more negative than progressive in GUMS (23). In both nursing and midwifery fields (SPL) interpreted A more positive perception, (SPT) in the midwifery field interpreted Model Instructors and in the nursing field Moving in the right direction, (SASP) in the midwifery field interpreted Confident and in the nursing field interpreted Feeling more on the positive side, (SPA) in both fields interpreted A good feeling overall, (SSSP) in both fields interpreted Not too bad, and (SPEE) in the midwifery field interpreted Excellent and in the nursing field interpreted More positive than negative.

This study was conducted in a single academic setting, but there was a significant difference between the (SPEE) of the two fields of study at the faculty. It is likely that this difference stems from other topics such as the nature of each discipline that goes beyond the topics discussed in this study. Perception of midwifery field students acquire greater mean than nursing students in all areas of the educational environment. It may be due to the interest in the field or probably that educational managers, midwifery teachers, clinics and society provide more facilities and respect to midwifery students than nursing students. This situation addresses educational managers to more consider nursing students for (SPL), (SPT), (SASP), (SPA) and (SSSP). In this study, there was weak correlation between (SPT) and GPA, (SASP) and GPA; moreover, there was weak correlation between (SPEE) and GPA. However, it is considerable that the lower number of midwifery students in this study than nursing students resulted from the correlation coefficient GPA with (SASP) and (SPEE) in two variables being weak and if the number of midwifery students increased, the result would be meaningful.

Biggs found that students who register in accelerated programs had significantly greater GPA's (24). Rotthoff found that students with higher grades assessed the climate to be better than did students with lower marks (25). In research, students' perception of their educational environment has been found to be related with their methods of learning and learning outcomes (26). In spite of this, Payne and Glaspie showed students' performance was not influenced by SPEE and results did not support the issues that SPEE of more positive than negative will significantly influence student outcomes (11). Although a few studies had found no correlation between perceptions of educational environment and students' performance, this study and other studies have found a significant relationship between perceptions of educational environment and GPA. It is required that more attention be paid to nursing and midwifery EC and the improvement of the learning environment and educational plans (27). Universities play an essential role in social development and it is necessary to make education and its practice intellectual, high quality and reasonably valued (28). Policymakers and planners need to pay more attention to nursing and midwifery EC and in particular clinical climate. Moreover, as well as considering a suitable physical, mental, psychological, and social environment, and also organizational culture teaching and learning issues and highly qualified teachers and role models, they need to reevaluate the creation of learning opportunities and make the essential efforts to progress the learning environment and educational plans, and make it more emphatic for nursing students due to the differences in nursing and midwifery. In general, raising the EC, will improve learning in students (29).

In this study, perceptions of EC of nursing students were lower than that of midwifery students in all dimensions. While both groups enter the university through an entrance exam, pass four years of college education in baccalaureate degree and study at a college, there was a difference in perception of the EC. Students and particularly nursing student perceptions of EC should be improved by educational managers in academies. Increasing students confidence about passing this year, will prepare nursing students for the profession, nursing students who have been in good preparation in previous course work for current course work will improve their ability to memorize all they need. Moreover, encouraging nursing students to learn a lot about empathy in their profession will develop their problem solving skills. Nursing students should be encouraged to participate during class, in classes, teaching over emphasizes factual learning, and long term learning is emphasized over short-term learning for nursing students. Educational managers should improve nursing student perceptions of EC in (SPT) through use of knowledgeable instructors who adopt a patient focused approach to clinical care, and by instructors who do not deride the students or are totalitarian instructors. Instructors who have good communication skills, provide good feedback to the registrar, offer constructive criticism, give clear examples, not become irritated in class and are well prepared for their class.

It is very important to find the cause of difference in means in nursing and midwifery students. The difference may be attributed to the greater attention of the community to midwifery, the greater attention of the school authorities 
and receiving positive feedback from them. In addition, this group of students can work independently in private clinics after graduation, they hope for a better future. The field of nursing in the community is not well acknowledged, and the services provided by nursing personnel in various settings have not yet been properly recognized in the community in general and in health organizations. Understanding nursing is still more affected by the same stereotyped image. Although nursing discipline has undergraduate, postgraduate and doctoral degrees, and has a variety of nursing fields, it still is not well recognized. It is proper that all nurses' efforts increase public admiration and give value to nursing. Furthermore, it emphasizes how nursing uniquely contributes to patients achieving their preferred health outcomes. Nursing's influences on public health must be acknowledged and proclaimed. It is suggested it is explored in a separate study and qualitative research to understand the cause of the weak (SPEE) of nursing students.

\section{Conclusions}

The results of this study indicate that there was significant difference in nursing and midwifery students in (SPL), (SPT), and (SASP) areas. Although nurses have high competency and abilities, for various reasons, this field has not yet been identified as much as it deserves in society and health organizations. This status addresses the responsibilities of nursing managers, nursing policymakers and nursing teachers to make more attempts toward forming an appropriate educational environment, and reducing deficits, in order to provide a better learning environment with supportive systems and more facilities for the students, and in particular, nursing students. Furthermore, authorities of health organizations and the media should provide, maintain and enhance the nursing position and nurses in all organizational categories. It is suggested that the reasons of this situation could be explained in a qualitative research. In this study, there was correlation between categories Perceptions of Teaching and GPA, and Academic self-perceptions and GPA. Moreover, there was correlation between perceptions of the educational environment and GPA, and there is opportunity for development of the educational environment.

\section{Acknowledgments:}

This paper is the result of an approved research project, funded by vice-chancellor for research (Hamadan University of Medical Sciences; ref. no.: 88061788283). The authors wish to thank all nursing and midwifery students for their great help in conducting this research.

\section{Conflict of Interest:}

There is no conflict of interest to be declared.

\section{Authors' contributions:}

Both authors contributed to this project and article equally. Both authors read and approved the final manuscript.

\section{References:}

1) Mohammadi S, Yazdan Nik AR, Yousefy A, Taj Mohammad A. A Glimpse in the Challenges in Iranian Academic Nursing Education. Iranian Journal of Medical Education. 2014; 14(4): 323-31.

2) Genn JM. AMEE Medical Education Guide No 23 (Part 1) Curriculum environment climate quality and change in medical education -a unifying perspective. Med Teach. 2001; 23(4): 337-44. doi: 10.1080/01421590120063330.

3) Roff S, McAleer S, What is educational climate? Med Teach. 2001; 23(4): 333-334. doi: 10.1080/01421590120063312.

4) Adelman Hea. National School Climate Council The School Climate Challenge: Narrowing the gap between school climate research and school climate policy, practice guidelines and teacher education policy. National Center for Learning and Citizenship (NCLC) an Education Commission of the States (ECS); 2007.

5) Tagiuri R. The concept of organizational climate. Organizational climate: Exploration of a concept. Boston, MA: Harvard University, Division of Research, Graduate School of Business Administration; 1968.

6) Genn JM. AMEE Medical Education Guide No. 23 (Part 2): Curriculum, environment, climate, quality and change in medical education - a unifying perspective. Med Teach. 2001; 23(5): 445-54. doi: 10.1080/01421590120075661. PMID: 12098364.

7) Lizzio A, Wilson K, Simons R. University students' perceptions of the learning environment and academic outcomes: implications for theory and practice. Studies in Higher Education. 2002; 27(1): 27-52. doi: 10.1080/03075070120099359. 
8) Karimi Moonaghi H, Ahanchian MR, Hassanian ZM. A Qualitative Content Analysis of Knowledge Storage in Nursing Education System. Iran Red Crescent Med J. 2014; 16(10): e21835. doi: 10.5812/ircmj.21835

9) Driessnack M, Mobily P, Stineman A, Montgomery LA, Clow T, Eisbach S. We are different. Learning needs of accelerated second-degree nursing students. Nurse Educator. 2011; 36(5): 214-8. doi: 10.1097/NNE.0b013e3182297c90.

10) Pimparyon P, Roff S, Mcaleer S, Poonchai B, Pemba S. Educational environment, student approaches to learning and academic achievement in a Thai nursing school. Med Teach. 2000; 22(4): 359e64. doi: 10.1080/014215900409456.

11) Payne LK, Glaspie T. Associations between baccalaureate nursing students' perceptions of educational environment and HES scores and GPA. Nurse Educ Today. 2014; 34(6): e64-8. doi: 10.1016/j.nedt.2013.10.014. PMID: 24238735.

12) Harden RM. The learning environment and the curriculum. Med Teach. 2001; 23(4): 335-6. doi: $10.1080 / 01421590120063321$.

13) Al-Hazimi A, Zaini R, Al-Hyiani A, Hassan N, Gunaid A, Ponnamperuma G, et al. Educational environment in traditional and innovative medical schools: a study in four undergraduate medical schools. Educ Health (Abingdon). 2004; 17(2): 192-203. doi: 10.1080/13576280410001711003. PMID: 15763762.

14) Tontus HO. DREEM; dreams of the educational environment as its effect on education result of 11 Medical Faculties of Turkey. Journal of Experimental and Clinical Medicine. 2010; 27: 104-8. doi: 10.5835/jecm.omu.27.03.002.

15) Roff S. The Dundee ready educational environment measure (DREEM)-a generic instrument for measuring students' perceptions of undergraduate health professions curricula. Med Teach. 2005; 27(4): 322-5. doi: $10.1080 / 01421590500151054$.

16) O'Brien A, Chan $T$, Cho $M$. Investigating nursing students' perceptions of the changes in a nursing curriculum by means of the dundee ready education environment measure (DREEM) inventory: Results of a cluster analysis. Int J Nurs Educ Scholarsh. 2008; 5(1): 1-18. doi: 10.2202/1548-923X.1503.

17) Edgren G, Haffling AC, Jakobsson U, Mcaleer S, Danielsen N. Comparing the educational environment (as measured by DREEM) at two different stages of curriculum reform. Med Teach. 2010; 32(6): e233ee8. doi: $10.3109 / 01421591003706282$.

18) Soltani Arabshahi K, Kouhpayezadeh J, Sobuti B. The Educational Environment of Main Clinical Wards in Educational Hospitals Affiliated to Iran University of Medical Sciences: Learners' Viewpoints Based on DREEM Model. Iranian Journal of Medical Education. 2008; 8(1): 43-9.

19) Lumsden R, Schofield S. Perceptions of Educational Climate in a Canadian Medical Radiation Science Programme. Journal of Medical Imaging and Radiation Sciences. 2011; 42: 124-9. doi: 10.1016/j.jmir.2011.06.002.

20) Cerón MC, Garbarini AI, Parro JF. Comparison of the perception of the educational atmosphere by nursing students in a Chilean university. Nurse Education Today. 2016; 36: 452-6. doi: 10.1016/j.nedt.2015.10.013.

21) Hassanian ZM, Ahanchian MR, Ahmadi S, Hossein Gholizadeh R, Karimi-Moonaghi H. Knowledge Creation in Nursing Education. Global Journal of Health Science 2015; 7(2): 44-55. doi: 10.5539/gjhs.v7n2p44.

22) Payne LK. Comparison of students' perceptions of educational environment in traditional vs. accelerated second degree BSN programs. Nurse Education Today. 2013; 33(2): 1388-92. doi: 10.1016/j.nedt.2012.11.003.

23) Taheri M. Students' perceptions of learning environment in Guilan University of Medical Sciences. Journal of Medical Education. 2009; 13(4): 126-33.

24) Biggs J, Tang C. Teaching for quality learning at university. Buckingham: Open University Press; 2011.

25) Rotthoff T, Ostapczuk MS, De Bruin J, Decking U, Schneider M, Ritz-Timme S. Assessing the learning environment of a faculty: psychometric validation of the German version of the Dundee Ready Education Environ-ment Measure with students and teachers. Med Teach. 2011; 33: 624-36. doi: 10.3109/0142159X.2011.610841. PMID: 22022916.

26) Haarala-Muhonen A, Ruohoniemi M, Katajavuori N, Lindblom-Ylanne S. Comparison of students' perceptions of their teaching-learning environments in three professional academic disciplines: A valuable tool for quality enhancement. Learn Environ Res. 2011; 14(2): 155-69. doi: 10.1007/s10984-011-9087-x. 
27) Anthony R. Artino, Jr. Academic self-efficacy: from educational theory to instructional practice. Perspect Med Educ. 2012 May; 1(2):76-85. doi: 10.1007/s40037-012-0012-5. PMCID: PMC3540350, PMID: 13316462.

28) Hassanian ZM, Oshvandi K. Comparison of nursing and midwifery students' perceptions of the educational environment. Int J Med Res Health Sci. 2016; 5(9S): 60-7.

29) Hassanian ZM, Ahanchian MR, Karimi-Moonaghi H. Can Knowledge Management Be Implemented in the Teaching of Medical Sciences? Acta Facultatis Medicae Naissensis. 2015; 32(4): 231-42. doi: 10.1515/afmnai-2015-0024.

30) Muhamad Y, Wan NA. Educational environment and psychological distress of medical students: The role of a deep learning approach. Journal of Taibah University Medical Sciences. 2015; 10(4): 411-8. doi: 10.1016/j.jtumed.2015.08.005. 